
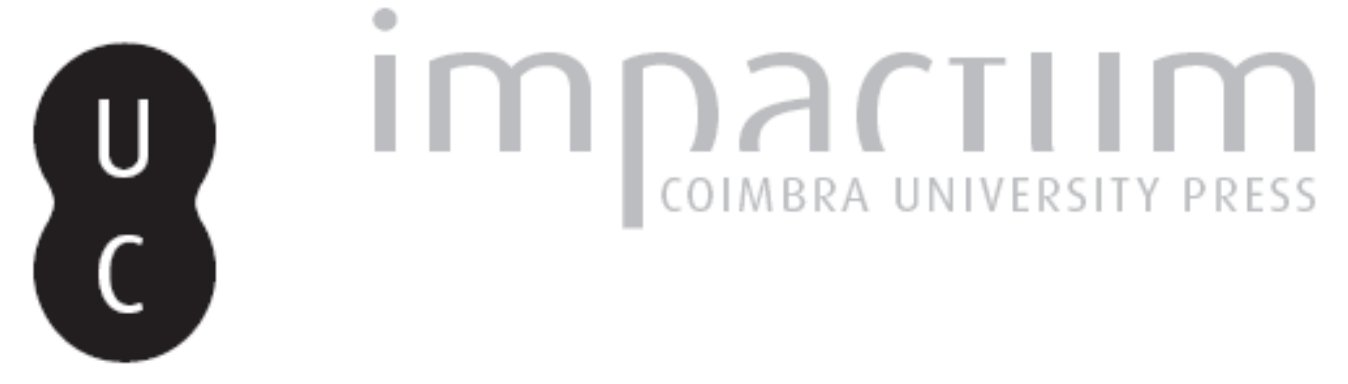

\title{
Coimbra como projecto urbano
}

\author{
Autor(es): Grande, Nuno
}

Publicado por: Editorial do Departamento de Arquitectura

URL persistente:

URI:http://hdl.handle.net/10316.2/37451

DOI:

DOI:http://dx.doi.org/10.14195/0874-6168_3_6

Accessed : $\quad$ 26-Apr-2023 03:42:21

A navegação consulta e descarregamento dos títulos inseridos nas Bibliotecas Digitais UC Digitalis, UC Pombalina e UC Impactum, pressupõem a aceitação plena e sem reservas dos Termos e Condições de Uso destas Bibliotecas Digitais, disponíveis em https://digitalis.uc.pt/pt-pt/termos.

Conforme exposto nos referidos Termos e Condições de Uso, o descarregamento de títulos de acesso restrito requer uma licença válida de autorização devendo o utilizador aceder ao(s) documento(s) a partir de um endereço de IP da instituição detentora da supramencionada licença.

Ao utilizador é apenas permitido o descarregamento para uso pessoal, pelo que o emprego do(s) título(s) descarregado(s) para outro fim, designadamente comercial, carece de autorização do respetivo autor ou editor da obra.

Na medida em que todas as obras da UC Digitalis se encontram protegidas pelo Código do Direito de Autor e Direitos Conexos e demais legislação aplicável, toda a cópia, parcial ou total, deste documento, nos casos em que é legalmente admitida, deverá conter ou fazer-se acompanhar por este aviso.

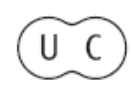




\section{ecdj $\quad z$}

fctuc|departamento de arquitectura

novos mapas para velhas cidades

guido giangregorio / walter rossa

rui lobo | álvaro domingues / nuno grande

joão paulo cardielos / josé antónio bandeirinha

workshop internacional de arquitectura

coimbra: um novo mapa [16 a 25 de novembro]

projectos

manuel graça dias margueira

manuel fernandes de sá marginal do douro antónio belém lima vila real

editores jorge figueira + nuno grande 


\section{[coimbra como projecto urbano]}

nuno grande

Durante os dez anos da sua existência, o Departamento de Arquitectura da Faculdade de Ciências e Tecnologia da Universidade de Coimbra tem procurado estabelecer uma relação operativa com a cidade que dá suporte ao meio académico em que se insere.

Essa relação tem sido reforçada pela participação dos seus docentes em inúmeras actividades extracurriculares, como Concursos, Júris, Colóquios ou Exposições, vincando, dessa forma, o papel fundamental que a concentração circunstancial de um colégio alargado de arquitectos e historiadores de arquitectura pode ter sobre a reflexão e o debate em torno da presente transformação da cidade.

> Para além disso, esta mesma cidade, tão contraditória na sua evolução e forma, constitui um excelente campo de experimentação e simulação projectada em diversas disciplinas académicas, permitindo aos docentes e alunos confrontarem-se com inúmeras facetas do próprio fenómeno urbano contemporâneo. Vejamos como se expressam aqui essas faces urbanas.

> Coimbra é, em certo sentido, similar a qualquer cidade europeia, de escala intermédia, que dificilmente gere e confronta uma forte e coesa herança histórica com um indefinido e disforme presente.

> Existe uma Coimbra reconhecível, mapificada, que faz parte dos roteiros turísticos e das visitas guiadas diárias que despejam centenas de turistas na Alta Universitária de máquina fotográfica em punho. Nessa cidadela, em horas de expediente, habita a chamada "comunidade académica" - professores, alunos, funcionários - que a abandona para lá da rotina, deixando os majestosos e brancos edifícios de calcário recortados na noite vazia. A restante Alta Coimbrã - a da Almedina ou do Jardim Botânico - não encerra população suficiente para contrariar a condição de ultra-dependência institucional e funcional que a cidade histórica criou em relação à Universidade. 


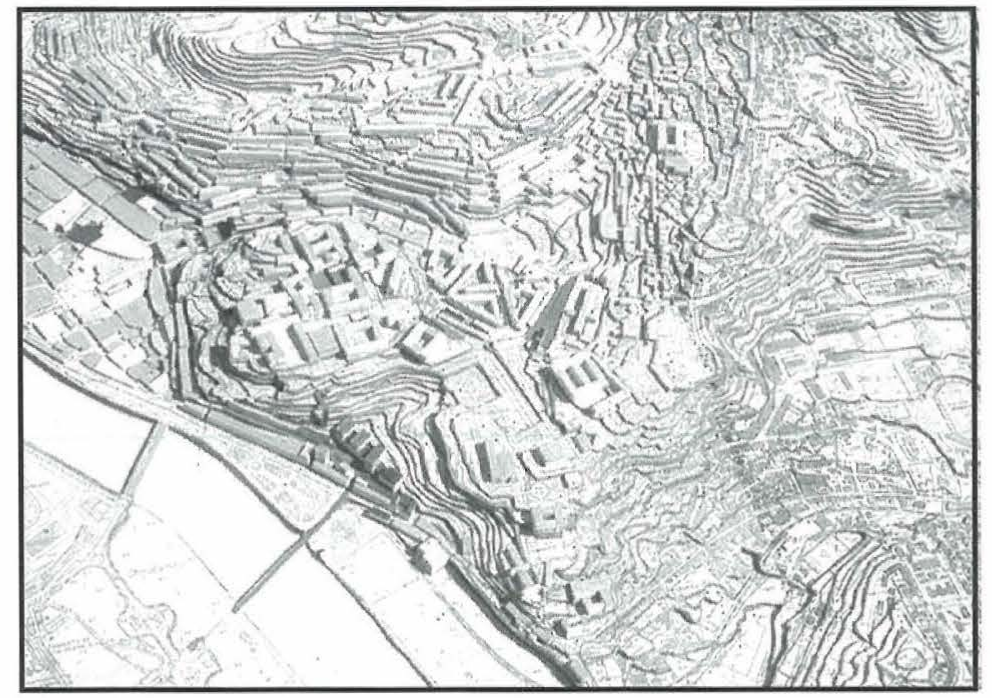

De resto, esta progressiva monofuncionalização atinge outras áreas como a

Avenida Sá da Bandeira ou a Baixinha, onde o comércio, a restauração ou outros serviços se destinam essencialmente à população académica ou ao turista de ocasião, sem que se sintam outros sinais de pluralidade ou cosmopolitismo. Neste sentido, assistiu-se, nas últimas décadas, a uma espécie de periferização do centro de Coimbra, visível nas inúmeras situações de esvaziamento e abandono a que foi votado o seu tecido consolidado.

> Existe, no entanto, uma outra Coimbra real, habitada, nova e empreendedora, que já não está na Alta dos doutores, na Avenida burguesa, nos colégios da Sofia ou nos choupais do Mondego; está antes, na coroa envolvente onde proliferam novos loteamentos, nos extensos bairros que ocupam os vales e os festos de outras colinas, nas fábricas e armazéns que se misturam com as moradias suburbanas. Ali residem os coimbrãos que todos os dias ocupam, em controlado caos, e abandonam, em incompreensível ordem, o centro histórico da cidade. Coimbra é, hoje, Seira, Arregaça, S. Martinho do Bispo, Souselas, Arrentela, Pedrulha e outros nomes que nunca constarão dos roteiros turísticos.

> As políticas urbanas mais recentes acreditaram na solução redentora, e à posteriori, do traçado de grandes infraestruturas como forma de dar sentido àquilo que cresceu aparentemente sem qualquer estrutura ou lógica planimétrica. Novos itinerários centrais, novos viadutos e acessos à cidade, novas circulares e até uma nova ponte "para a Europa", procuram reencontrar um sentido de coesão que teima em não existir.

Algures, nessas cicatrizes que os novos acessos procuram domesticar, ocupando os vales entre a cidade estabilizada e esses outros fragmentos, para lá das circulares, das margens do Mondego e das linhas de festo, desenha-se uma "outra cidade" ainda sem forma ou conteúdo. Nesses limites, que são também inícios de coisa incerta, concentra-se o grande potencial de transformação desta cidade, das suas forças vivas, 
da sua identidade futura. Torna-se por isso fundamental, identificar e consolidar essa nova estrutura urbana sem a qual Coimbra não conseguirá libertar-se do estigma de uma cidade em desagregação.

> Nos últimos anos, o Departamento de Arquitectura da F.C.T.U.C., na sua disciplina de Projecto Urbano do $5^{\circ}$ ano, tem vindo precisamente a centrar os seus exercícios em torno da descodificação deste centro urbano, assaltado por fenómenos de periferização e, simultaneamente, dessa coroa periférica vital para a identificação da cidade alargada.

Nessa simulação, entram dados reais fornecidos pelo Município, expectativas do mercado imobiliário, apontamentos dos planos em curso ou interrompidos e a impressão analítica de cada grupo de alunos sobre o espaço físico em estudo, expressa nas surpreendentes maquetes territoriais com que se enchem os estiradores; desenvolve-se, sobretudo, um constante esforço de síntese e uma operatividade projectual que são caros à orientação de Gonçalo Byrne, coordenador da disciplina.

> O desafio lançado aos alunos reside, então, na tentativa de qualificação dos nós que atam essa rede complexa de dispersões territoriais, pedindo-lhes que desenhem esse "novo mapa" da cidade, onde se espera que o todo seja mais do que o somatório das partes e onde o caos não seja apenas o contrário da ordem.

> Na abordagem do Projecto Urbano ao centro - na área da Alta Universitária e da Baixinha - esse "mapa" tem vindo a desenhar-se essencialmente sobre a reconversão funcional de inúmeros edifícios institucionais, peças de grande porte na cidade que lentamente vão perdendo a sua actual função - quartéis militares, penitenciária, mercado central, depósitos camarários, instalações da EDP, etc... - conjugando-os com novas articulações de acesso às cotas altas - espaços e percursos pedonais, ascensores, parques de estacionamento - acrescentando outros layers a esse palimpsesto que define o tecido consolidado.

> Nos exercícios efectuados nas frentes de água da cidade, assume-se o Mondego como um enorme espelho de água lúdico e capaz de refazer a ligação urbana entre as duas margens. Na revitalização dessas frentes, os alçados urbanos jogam um papel fundamental, medido nas novas escalas que interrompem a cércea média dos antigos armazéns ferroviários abandonados, de um lado, ou do conjunto de equipamentos desportivos universitários subaproveitados, do outro. De novo, aqui tenta-se manter memórias de uma cidade monofuncionalizada, conjugando-as com novas escalas e funções, para as quais a melhoria das ligações entre margens é fundamental - refira-se aqui a prevista introdução nos próximos projectos municipais de um sistema de eléctrico rápido que servirá a margem direita e de uma ponte pedonal sobre o Mondego.

> Mas é precisamente nas franjas de transição periférica que o exercício propõe a identificação dessa cidade informe que define hoje a urbanidade de Coimbra. Constata-se dos resultados apresentados por diversos grupos de alunos que as grandes infraestruturas viárias e ferroviárias - circulares urbanas, nós rodoviários, interfaces de transportes - jogam um papel 
preponderante na qualificação dos novos territórios. Traçados pouco sensíveis à conformação desses territórios ou mal resolvidos no contacto com escalas urbanas precedentes têm sido responsáveis pela desagregação dos novos loteamentos urbanos e pela proliferação de faixas residuais de terreno.

> O Projecto Urbano propõe, antes de mais, a reformulação desses traçados nas infraestruturas existentes e a implantação cuidada dos novos equipamentos previstos. Como exemplo, apontam-se trabalhos desenvolvidos na definição das frentes urbanas da Circular Interna à cidade, nos seus extensos vales, ou no desenho do novo interface da Linha do Norte, em Coimbra B (até hoje, incompreensivelmente indefinido pelos diversos programas ferroviários nacionais). Desta forma, os alunos projectam programas e espaços nevrálgicos capazes de introduzir identidades locais até hoje inexistentes, compreendendo como outrora os velhos conventos e colégios foram também eles essenciais para a consolidação da cidade universitária.

> Na formação final dos seus alunos, o Departamento de Arquitectura considera assim fundamental, o estabelecimento de uma relação conceptual entre a cidade consolidada, que Ihes é tão próxima, e essa "outra cidade" que permanece por identificar. Propõe-Ihes, para isso, o desenho desse "novo mapa" metafórico e geográfico da cidade alargada, o qual constitui, afinal, o mapa de qualquer cidade herdada que procura resgatar para si uma condição contemporânea.
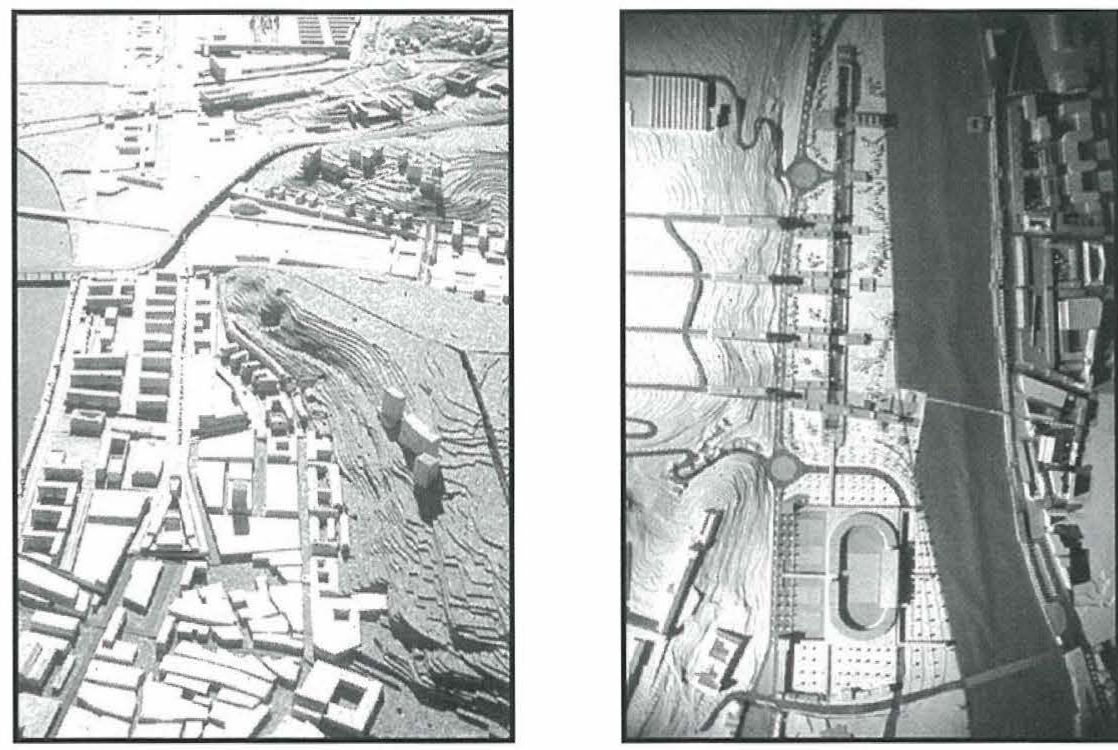